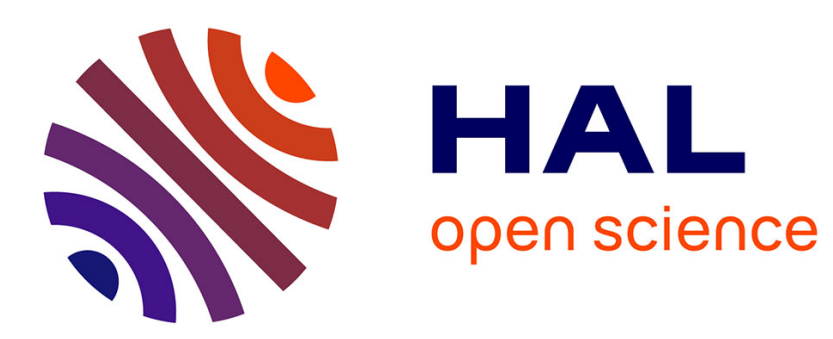

\title{
Explicit Lagrange Multiplier for Firms Facing a Debt Ceiling Constraint
}

\author{
Jean-Bernard Chatelain
}

\section{To cite this version:}

Jean-Bernard Chatelain. Explicit Lagrange Multiplier for Firms Facing a Debt Ceiling Constraint. Economics Letters, 2000, 67 (2), pp.153-158. 10.1016/S0165-1765(99)00270-0 . halshs-00119408

\section{HAL Id: halshs-00119408 https://shs.hal.science/halshs-00119408}

Submitted on 9 Dec 2006

HAL is a multi-disciplinary open access archive for the deposit and dissemination of scientific research documents, whether they are published or not. The documents may come from teaching and research institutions in France or abroad, or from public or private research centers.
L'archive ouverte pluridisciplinaire HAL, est destinée au dépôt et à la diffusion de documents scientifiques de niveau recherche, publiés ou non, émanant des établissements d'enseignement et de recherche français ou étrangers, des laboratoires publics ou privés. 


\title{
Explicit Lagrange Multiplier for Firms Facing a Debt Ceiling Constraint
}

\author{
Jean-Bernard CHATELAIN* \\ Post Print: Economics Letters (2000), 67, pp. 153-158.
}

\begin{abstract}
This paper provides the explicit expression of investment facing a binding debt ceiling and the explicit expression of the Lagrange multipliers related to the binding debt ceiling constraint. This result allows to check for misspecification of the parameterizations of these Lagrange multipliers used in Euler investment equations tests during the 1990's.
\end{abstract}

JEL Classification: D92 G32。

Keywords: Investment, Credit Rationing.

\section{Introduction}

Recent papers tested the Euler equation for capital of the neoclassical model of investment for an infinetely living firm facing quadratic adjustment costs, taxation, imperfect competition on the goods market and an exogenous debt ceiling constraint (see e.g. Gertler et al. [1990], Whited [1992] and subsequent papers surveyed in Schiantarelli [1996]). In his Journal of Economic Literature survey on the economics of investment, Chirinko ([1993] pp.1902-1904) mentioned that, in these Euler equation tests, "the endogenous variables that parameterize the Lagrange multiplier related to this [borrowing] constraint (such as cash flow and net worth) are not accounted for explicitly in specifying the econometric equation, thus blurring econometric interpretations of the statistical tests. It remains uncertain whether significant liquidity and net worth variables are capturing a structural element heretofore missing in the investment equation or are merely reflecting general misspecification." This Lagrange multiplier is parameterized in an ad hoc fashion in the belief that "the first order conditions do not provide an analytical answer" (Whited [1992, p. 1435]). In this note, we provide the analytical answer which was missing. This Lagrange multiplier is related to the

*PSE, Cepremap and Economix, University Paris 10. E-mail address: jean-bernard.chatelain@uparis10.fr 
gap between the standard neoclassical investment behaviour and the (explicit) credit constrained investment. Both expressions are derived in this note, which allows to check for misspecification in these empirical works.

\section{Explicit Lagrange Multiplier}

The standard partial equilibrium neoclassical model of investment begins with an expression for the value of the firm, which in turn stems from the arbitrage condition governing the valuation of shares. The after-tax return to the owners of the firm at time $t$ reflects capital appreciation and current dividends. In equilibrium, if the owners are to be content holding their shares, this return must equal $\left(1-m_{t}\right) r_{t}^{0}$ the after tax nominal return on riskless (government) bonds between period $t$ and period $t+1\left(r_{t}^{0}\right.$ represents the nominal return before income tax and $m_{t}$ is the personal income tax on dividends and interest income in period $t$ ):

$$
\frac{\left(1-c_{t}\right)\left(E_{t}\left[V_{i, t+1}-S_{i, t+1}\right]-V_{i t}\right)+\left(1-m_{t}\right) \theta_{t} E_{t}\left[d_{i, t+1}\right]}{V_{i t}}=\left(1-m_{t}\right) r_{t}^{0}
$$

where $V_{i t}$ is the value of the firm $i$ at time $t, S_{i t}$ denotes the value of new shares issued at time $t+1, c_{t}$ is the accrual-equivalent capital gains tax rate, $\theta_{t}$ is the dividend received by the shareholder when the firm distributes one unit of post-corporate tax earnings ${ }^{1}$. Therefore, the taxe rate on dividends is $\left(1-m_{t}\right) \theta_{t}$. $E_{t}$ is the expectation operator conditional on information known at time $t$. The after-tax capital gain of the current shareholders thus consists of the change in the market value of the firm less the component of this change due to new share issues. The tax discrimination parameter $\gamma_{t}=\left(1-m_{t}\right) \theta_{t} /\left(1-c_{t}\right)$ determines the relative tax advantage of dividend income against capital gains. The dividends of the firm $i$ at time $t$ are $d_{i t}$. In the absence of bubbles, solving the capital market arbitrage condition yields the following expression for the firm's market value at time zero:

$$
\max _{\left\{p_{i t}, I_{i t}, L_{i t}, d_{i t}, S_{i t}, K_{i t}, B_{i t}\right\}_{t=0}^{\infty}} V_{i, t=0}=E_{t} \sum_{t=0}^{t=+\infty}\left(\prod_{s=0}^{s=t-1} \beta_{i s}\right)\left(\gamma_{t} d_{i t}-S_{i t}\right)
$$

where the firm's one period nominal discount factor is:

$$
\beta_{i t}=\frac{1}{1+\left(\frac{1-m_{t}}{1-c_{t}}\right) r_{t}^{0}}
$$

The entrepreneur in firm $i$ chooses dividends, investment, labour and price of output in maximizing the present value of dividends $d_{i, t}$ on date $t$ in a infinite horizon, with the discounted rate of the opportunity cost of internal funds, subject to several

\footnotetext{
${ }^{1}$ Under an imputation relationship between corporate and personal taxes, the parameter $\theta_{t}=$ $1 /\left(1-s_{t}\right)$ where $s_{t}$ is the rate of imputation. Under a classical relationship, $\theta_{t}$ is simply unity.
} 
constraints. The "flow of funds" constraint defines firm dividends. Cash inflows include sales, new share issues, and net borrowing, while cash outflows consist of dividends, factor and interest payments, and investment expenditures:

$$
\begin{aligned}
d_{i t}= & (1-\tau)\left(p_{i t} F\left(K_{i, t-1}, N_{i t}\right)-p_{i t} \Psi\left(I_{i t}, K_{i, t-1}\right)-w_{t} N_{i t}-i_{t-1} B_{t-1}\right) \\
& +S_{i t}+B_{i t}-B_{i, t-1}-p_{i t}^{I} I_{i t},
\end{aligned}
$$

where $I_{i t}$ is its investment at time $t, K_{i t}$ is capital, $N_{i t}$ a vector of variable factors of production for firm $i$ at time $t, F\left(K_{i, t-1}, N_{i t}\right)$ the firm's revenue function $\left(F_{K}>\right.$ $\left.0, F_{K K}<0\right), \Psi\left(I_{i t}, K_{i, t-1}\right)$ the cost of adjusting the capital stock $\left(\Psi_{I}>0, \Psi_{I I}>0\right.$, $\left.\Psi_{K}<0, \Psi_{I K}<0\right), w_{t}$ a vector of nominal factor prices at time $t, i_{i t}$ the nominal interest rate on debt at time $t, B_{i t}=$ the value of net debt outstanding for firm $i$ at time $t, p_{i t}=$ the price of final goods at time $t, p_{i t}^{I}=$ the price of capital goods at time $t$ (incorporating tax considerations); $\tau=$ the corporate income tax rate, against which interest payments are assumed to be deductible.

The firm faces the capital accumulation constraint (with a related Lagrange multiplier $\left.\lambda_{i t}^{K}\right): K_{i t}=I_{i t}+(1-\delta) K_{i, t-1}$ where $\delta$ a constant rate of economic depreciation, an exogenous debt ceiling constraint $\left(B_{i t} \leq B_{i t}^{*}\right.$, related Lagrange multiplier $\left.\lambda_{i t}^{B}\right)$, and a positivity of dividends constraint $\left(d_{i t} \geq 0\right.$, related Lagrange multiplier $\left.\lambda_{i t}^{d}\right)$. The firm also faces a downward sloping demand function $\varphi\left(p_{i t}\right)$ for its product with an absolute value of the elasticity denoted $e=-\varphi^{\prime}\left(p_{i t}\right) p_{i t} / \varphi\left(p_{i t}\right)$. Demand is equal to supply, i.e. output net of adjustment costs, so that the value of sales is the following function of inputs after inversion of the demand function: $\varphi^{-1}\left(F\left(K_{i, t-1}, N_{i t}\right)-\Psi\left(I_{i t}, K_{i, t-1}\right)\right)\left[F\left(K_{i, t-1}, N_{i t}\right)-\Psi\left(I_{i t}, K_{i, t-1}\right)\right]$. The derivative of sales with respect to an input $X$ is therefore:

$$
\left[1+\frac{\left[F\left(K_{i, t-1}, N_{i t}\right)-\Psi\left(I_{i t}, K_{i, t-1}\right)\right]}{p_{i t}}\left[\varphi^{-1}\right]^{\prime}\right] p_{i t}\left[F_{X}\left(K_{i, t-1}, N_{i t}\right)-\Psi_{X}\left(I_{i t}, K_{i, t-1}\right)\right]
$$

I denote the inverse of the markup factor $\mu=1-\frac{1}{e}>0$. The case of a price taker perfect competitor is given by setting the parameter $\mu$ to unity each time it appears before the output price in the following equations.

Dividends are substituted directly in the Lagrangean, using the flow of funds constraint as well as investment by the capital accumulation equation. The first order conditions for capital $K_{i t}$ (Euler equation) is:

$$
\begin{aligned}
& E_{t} \beta_{i t}\left[\frac { \gamma _ { t + 1 } + \lambda _ { i , t + 1 } ^ { d } } { \gamma _ { t } + \lambda _ { i t } ^ { d } } \left[\mu p_{i, t+1} F_{K}\left(K_{i t}, N_{i t+1}\right)-\mu p_{i, t+1} \Psi_{K}\left(I_{i, t+1}, K_{i t}\right)+\right.\right. \\
& \left.\left.(1-\delta) \mu p_{i, t+1} \Psi_{I}\left(I_{i, t+1}, K_{i, t}\right)+\frac{(1-\delta) p_{i, t+1}^{I}}{1-\tau_{t+1}}\right]\right] \\
= & p_{i t} \mu \Psi_{I}\left(I_{i, t}, K_{i, t-1}\right)+\frac{p_{i t}^{I}}{1-\tau_{t}}
\end{aligned}
$$


In the Euler equation for capital, the discount factor turns to be "corrected" by a multiplicative factor $\Gamma_{i t}=\left(\gamma_{t+1}+\lambda_{i, t+1}^{d}\right) /\left(\gamma_{t}+\lambda_{i, t}^{d}\right)$. The marginal condition for debt is:

$$
E_{t} \beta_{i t} \Gamma_{i t}=\frac{1-\frac{\lambda_{i t}^{B}}{\gamma_{t}+\lambda_{i t}^{d}}}{1+\left[1-\tau_{t+1}\right] i_{i t}}
$$

It reveals that the "corrected" discount factor $\beta_{i t} \Gamma_{i t}$ is equal to a discount factor using the net of tax marginal cost of debt as a discount rate if $\lambda_{i t}^{B}=0$, and else that the discount factor decreases with the Lagrange multiplier of the debt ceiling constraint (i.e. the discount factor should use the shadow interest rate that would have accepted the firm if she was not facing a quantitative constraint).

$\Gamma_{i t}$ has been parameterized in an ad hoc manner in several papers following the first ones surveyed by Chirinko [1993]. The aim of this note is to find its explicit form, which amounts to find the explicit form for $\lambda_{i t}^{d}$. The Lagrange multiplier related to a quantitative constraint is generally an increasing function of the gap between the "notional" denoted $I_{i t}^{U C}$ and the "constrained" control variable (investment for the firm facing credit rationing) denoted $I_{i t}^{C}$. The expression $\gamma_{t}+\lambda_{i t}^{d}$ is given by the marginal condition on investment in the credit rationing regime:

$$
\gamma_{t}+\lambda_{i t}^{d}=\frac{\lambda_{i t}^{K}}{p_{i t}^{I}+\mu p_{i t}\left(1-\tau_{t}\right) \Psi_{I}\left(I_{i t}^{C}, K_{i, t-1}\right)}
$$

where the marginal costate variable $\lambda_{i t}^{K}$ is given by the marginal condition on investment in the unconstrained regime $\left(\lambda_{i t}^{d}=0\right)$ :

$$
\lambda_{i t}^{K}=\gamma_{t}\left[p_{i t}^{I}+\mu p_{i t}\left(1-\tau_{t}\right) \Psi_{I}\left(I_{i t}^{U C}, K_{i, t-1}\right)\right]
$$

It is a function of the investment rate $I_{i t}^{U C}$ that would have chosen the firm in the absence of financial constraint. A structural specification of $\Gamma_{i t}$ is therefore given by:

$\Gamma_{i t}=\frac{p_{i t}^{I}+\mu p_{i t}\left(1-\tau_{t}\right) \Psi_{I}\left(I_{i t}^{C}, K_{i, t-1}\right)}{\gamma_{t}\left[p_{i t}^{I}+\mu p_{i t}\left(1-\tau_{t}\right) \Psi_{I}\left(I_{i t}^{U C}, K_{i, t-1}\right)\right]} \frac{\gamma_{t+1}\left[p_{i, t+1}^{I}+\mu p_{i, t+1}\left(1-\tau_{t+1}\right) \Psi_{I}\left(I_{i, t+1}^{U C}, K_{i t}\right)\right]}{p_{i, t+1}^{I}+\mu p_{i, t+1}\left(1-\tau_{t+1}\right) \Psi_{I}\left(I_{i, t+1}^{C}, K_{i t}\right)}$

\section{The case of quadratic adjustment costs}

I parameterize the adjustment cost function with its usual quadratic form $\Psi\left(I_{i t}, K_{i, t-1}\right)=$ $\frac{\alpha}{2}\left(\frac{I_{i, t}}{K_{i, t-1}}-\nu\right)^{2} K_{i, t-1}$ (Whited [1992]), so that $\Psi_{I}\left(I_{i t}, K_{i, t-1}\right)=\alpha\left(\frac{I_{i, t}}{K_{i, t-1}}-\nu\right)$. The next step is to solve for the investment solution facing a binding debt constraint $\left(I_{i t}^{C}\right)$ or not $\left(I_{i t}^{U C}\right)$.

On the one hand, when the firm does not face a debt constraint, the usual form is derived by a local approximation near the equilibrium, on the unique stable path. The 
standard textbook result is that current investment net of long run investment (which has only to replace the depreciation of the long run capital stock) is a linear function of the wedge between the current capital stock and the long term capital stock:

$$
I_{i t}^{U C}=\delta K_{i t}^{*}+(\sigma-1)\left(K_{i t}-K_{i t}^{*}\right)
$$

$K_{i t}^{*}$ is the long run stock of capital, defined by the Euler equation with stationary values (it depends on the marginal cost of capital on date $t$ corrected by the marginal adjustment costs of long term investment). $\sigma$ is the eigenvalue of the linearised dynamical discrete time system with an absolute value below one:

$$
\sigma=\frac{1}{2}\left[1+\frac{1}{\beta_{i t} E_{t} \frac{p_{i, t+1}}{p_{i t}}}-\sqrt{\left(1-\frac{1}{\beta_{i t} E_{t} \frac{p_{i, t+1}}{p_{i t}}}\right)^{2}-\frac{4 K_{i t}^{*} F_{K K}\left(K_{i t}^{*}, N_{i t}^{*}\right)}{\alpha}}\right]
$$

On the other hand, when the firm faces a binding debt ceiling constraint, the flow of funds equation can be written in the binding debt ceiling regime on date $t$ $\left(B_{i t}=B_{i t}^{*}\right)$, with no dividends $\left(d_{i t}=0\right)$ and with no new share issues $\left(S_{i t}=0\right)$ :

$$
\begin{aligned}
0= & (1-\tau)\left(p_{i t} F\left(K_{i, t-1}, N_{t}\right)-p_{i t} \frac{\alpha}{2}\left(\frac{I_{i, t}}{K_{i, t-1}}-\nu\right)^{2} K_{i, t-1}-w_{t} N_{t}-i_{i, t-1} B_{t-1}\right) \\
& +B_{i t}^{*}-B_{i, t-1}-p_{i t}^{I} I_{i t}
\end{aligned}
$$

Dividing the flow of funds equation by the capital stock $p_{i, t-1}^{I} K_{i, t-1}$ and using the capital accumulation relation $\left(K_{i t}=I_{i t}+(1-\delta) K_{i, t-1}\right)$, it follows a quadratic equation for the ratio of the investment rate $j_{i t}=I_{i t} / K_{i, t-1}$ depending on the ceiling of the debt/capital ratio $x_{i t}^{*}=B_{i t}^{*} / p_{i t}^{I} K_{i t}$ :

$$
\begin{aligned}
0= & (1-\tau)\left(\pi\left(K_{i, t-1}, N_{i t}\right)-p_{i t} \frac{\alpha}{2}\left(j_{i t}-\nu\right)^{2}-i_{i, t-1} x_{i, t-1}\right) \\
& +x_{i t}^{*} \frac{p_{i t}^{I}}{p_{i, t-1}^{I}}\left[j_{i t}+1-\delta\right]-x_{i, t-1}-\frac{p_{i t}^{I}}{p_{i, t-1}^{I}} j_{i t}
\end{aligned}
$$

$\pi\left(K_{i, t-1}, N_{i t}\right)=\left[p_{i t} F\left(K_{i, t-1}, N_{t}\right)-w_{t} N_{t}\right] / p_{i t}^{I} K_{i t}$ represents the profit rate. The investment rate is an explicit solution of the quadratic equation:

$$
\begin{array}{cl}
0= & -(1-\tau) p_{i t} \frac{\alpha}{2} j_{i t}^{2}+\left[(1-\tau) p_{i t} \frac{\alpha}{2} 2 v+\frac{p_{i t}^{I}}{p_{i, t-1}^{I}}\left(x_{i t}^{*}-1\right)\right] j_{i t}+C_{i t} \\
\text { where }: \quad & C_{i t}=-(1-\tau) p_{i t} \frac{\alpha}{2} v^{2}+(1-\tau) \pi\left(K_{i, t-1}, N_{i t}\right) \\
& +x_{i t}^{*} \frac{p_{i t}^{I}}{p_{i, t-1}^{I}}[1-\delta]-\left[1+(1-\tau) i_{i, t-1}\right] x_{i, t-1}
\end{array}
$$


so that ${ }^{2}$ :

$$
\begin{aligned}
j_{i t}^{C}\left(B_{i t}^{*}\right)= & v+\frac{p_{i t}^{I}}{p_{i, t-1}^{I}} \frac{x_{i t}^{*}-1}{(1-\tau) \alpha p_{i t}} \\
& +\sqrt{\left[v+\frac{p_{i t}^{I}}{p_{i, t-1}^{I}} \frac{x_{i t}^{*}-1}{(1-\tau) \alpha p_{i t}}\right]^{2}-2 \frac{C_{i t}}{(1-\tau) \alpha p_{i t}}}
\end{aligned}
$$

The first term of the Taylor development of this expression with respect to $\alpha$, the adjustment cost parameter, which is reasonably below one and small, leads to the following expresssion (it corresponds to the case $\alpha=0$, i.e. there are no adjustment costs):

$$
j_{i t}^{C}\left(B_{i t}^{*}\right)=\frac{(1-\tau)\left(p_{i t} F\left(K_{i, t-1}, N_{t}\right)-w_{t} N_{t}-i_{i, t-1} B_{t-1}\right)}{p_{i t}^{I} K_{i, t-1}}+\frac{B_{i t}^{*}-B_{i, t-1}}{p_{i t}^{I} K_{i, t-1}}
$$

Investment depends on after tax cash-flow from operating activities and on the variation of debt. Squared terms of these variables could be added if one takes into account the second order Taylor development with respect to $\alpha$.

Explanatory variables of $\Gamma_{i t}$ are the explanatory variables of the financially constrained investment and of the unconstrained investment function. $\Gamma_{i t}$ can also be linearised for a small adjustment cost parameter. Then, explanatory variables are the first differences of the variables determining investment facing credit rationing (cash flow from operating activities and the variation of debt) and of the variables related to the unconstrained investment level (the current size of capital of the firm $K_{i t}$ and the cost of capital, which determines the long run stock of capital $K_{i t}^{*}$ ). This explicit Lagrange multiplier suggests specifications closer to the structural one for Euler equation tests of financial constraints. For example, Whited [1992] intuitions for the choice of the financial variables were right. But these variables ought to have appeared in first difference in $\Gamma_{i t}$. Then, variables related to the unconstrained investment such as the current size of the capital stock and the cost of capital were omitted. Finally, the estimated parameters related to these extra financial variables were not constrained whereas they cannot be anything else than a combination of the parameters to be estimated in the optimization model written at the very beginning, i.e. the mark-up rate $\mu$ and the coefficient of adjustment $\operatorname{costs} \alpha$.

\section{Conclusion}

This note derives the explicit expression of investment facing a debt ceiling and of the Lagrange multiplier related to a binding debt ceiling constraint. These two results may

\footnotetext{
${ }^{2}$ If the adjustment cost parameter $\alpha$ is small enough, then one obtains $v+\frac{p_{i t}^{I}}{p_{i, t-1}^{I}} \frac{x_{i t}-1}{(1-\tau) \alpha p_{i t}}<0$, (the ceiling of the debt/capital ratio $x_{i t}$ is necessarily below one). The second solution for investment is negative, and therefore irrelevant for the behaviour of a firm facing a debt ceiling constraint.
} 
help to precise and develop tests on investment facing capital market imperfections.

\section{References}

[1] Chirinko R.S. [1993]. Business Fixed Investment Spending: A Critical Survey of Modeling Strategies, Empirical Results, and Policy Implications. Journal of Economic Literature. pp.1875-1911.

[2] Gertler M., Hubbard G. and Kashyap A. [1990]. Interest Rate Spreads, Credit Constraints, and Investment Fluctuations: An Empirical Investigation. NBER working paper 3495 .

[3] Schiantarelli F. [1996]. "Financial Constraints and Investment: Methodological Issues and International Evidence". Oxford Review of Economic Policy. 12(2). pp. 70-89.

[4] Whited T.M. [1992]. "Debt, Liquidity Constraints and Corporate Investment : Evidence from Panel Data." Journal of Finance. 47(4), pp.1425-1460. 